\title{
Synthesis of Nano Zno Powder and Study of Its Varistor Behavior at Different Temperatures
}

\author{
P. K. Roy ${ }^{1}$ \\ ${ }^{1}$ CG Global R\&D Center, AMPTC Lab, Crompton Greaves Ltd., Mumbai, India \\ Correspondence: P. K. Roy, CG Global R\&D Center, AMPTC Lab, Crompton Greaves Ltd. Mumbai - 400042, \\ India. E-mail: pradip.nitrkl@gmail.com
}

Received: July 1, 2012 Accepted: July 23, 2012 Online Published: August 15, 2012

doi:10.5539/jmsr.v1n4p28 URL: http://dx.doi.org/10.5539/jmsr.v1n4p28

\begin{abstract}
Commercial $\mathrm{ZnO}$ varistor ceramics are multi-component, with minor amounts of added oxides that play important roles, both in electrical sense and to control microstructure. The emphasis of this paper is mainly on improving the electrical properties and the effect of nano $\mathrm{ZnO}$ powder on varistor behavior. Ultra fine $\mathrm{ZnO}$ powders with crystallite size 3-10nm have been prepared by sol-gel auto combustion method. The synthesized powders characterized by X-ray diffraction (XRD), differential thermal analysis (DTA)/thermogravimetry analysis (TGA), transmission electron microscopy (TEM) and surface area using Brunauer-Emmett-Teller (BET) method. Different valance state elements in oxide form are additively doped with nano $\mathrm{ZnO}$ powder for fabrication of varistors. Sintering is performed at 850 to $1150^{\circ} \mathrm{C}$ with $4 \mathrm{~h}$ soaking time. The varistor is characterized with respect to phase identification, crystallite size determination using X-ray Diffraction. The densification and microstructure analysis using scanning electron microscope (SEM) are also investigated. It is shown that the varistor is mainly consisting of $\mathrm{ZnO}, \mathrm{Zn}_{7} \mathrm{Sb}_{2} \mathrm{O}_{12}$ spinel and $\mathrm{Bi}_{2} \mathrm{O}_{3}$-rich phases. It can be produced having a sintered density $\sim 99 \%$ of its theoretical density with grain size $\sim 5-7 \mu \mathrm{m}$ and a maximum breakdown voltage $292 \mathrm{~V} / \mathrm{mm}$.
\end{abstract}

Keywords: ceramics, nano zinc oxide, varistor, non-linear effect

\section{Introduction}

ZnO-based Varistors are widely used in protecting power and signal level electrical circuits against dangerous voltage surges. In order to optimize specific protection needs and device size requirements it is desirable to control varistor characteristics. Numerous investigators (Matsuoka, 1971; Snow et al., 1980; Asokan et al., 1987; Hennings et al., 1990) have studied the effects of processing and microstructure on electrical conduction in $\mathrm{ZnO}$ varistors. The most desirable device should have a high value of nonlinear co-efficient, an acceptable rating of nonlinear voltage, a low value of leakage current, a long varistor life, and a high energy absorption capability (Gupta, 1990). Varistors used in high voltage applications should have a relatively smaller grain size (5-10 $\mu \mathrm{m})$ so as to keep the varistor volume low. It is proposed that the addition of aluminum at the $125 \mathrm{ppm}$ level inhibits grain growth (Rahaman et al., 1990). Hot-pressing techniques have been successfully employed to reduce grain size and porosity (Snow et al., 1980).

It is well known, energy-handling capability is one of the most important requirements attendant on the application of the varistors for transient surge suppression. The capability of the $\mathrm{ZnO}$ varistors is dependent not only on the composition and processing procedure, but also on the uniformity of the sintered body of the devices (Boutonet et al., 1982). Otherwise, the inhomogeneity of the sintered microstructure will make $\mathrm{ZnO}$ varistors fail by puncturing, which is caused by local melting, when the $\mathrm{ZnO}$ varistors are subjected to high energy pulses (Konno et al., 1984). Nano particles yield a narrow grain size distribution and excellent stability against grain growth. They sinter at a lower temperature than do coarser grained ceramics, retaining their ultra fine grain size after sintering to full density, and exhibit superior properties as well (Siegel, 1990).

In order to get such uniform nano particles with a narrow size distribution, the sol-gel auto combustion process for nano $\mathrm{ZnO}$ synthesis provides an efficient way to decrease the grain size. In our laboratory, small uniform and nano $\mathrm{ZnO}$ powders for the fabrication of $\mathrm{ZnO}$ varistors are obtained by the auto combustion method. We have used the nano $\mathrm{ZnO}$ particles for varistor fabrication, and they have shown higher electrical properties and homogeneous microstructures. In the present work, we have studied $\mathrm{Bi}_{2} \mathrm{O}_{3}-\mathrm{Sb}_{2} \mathrm{O}_{3}-\mathrm{CoO}-\mathrm{MnO}_{2}-\mathrm{Cr}_{2} \mathrm{O}_{3}-\mathrm{SiO}_{2}$ doped 
$\mathrm{ZnO}$ nano powders under varying sintering temperatures. Densification, microstructure and electrical properties are also investigated.

\section{Method}

Analytical grade zinc nitrate $\left[\mathrm{Zn}\left(\mathrm{NO}_{3}\right)_{2} \cdot 6 \mathrm{H}_{2} \mathrm{O}\right]$ and citric acid $\left[\mathrm{C}_{6} \mathrm{H}_{8} \mathrm{O}_{7} \cdot \mathrm{H}_{2} \mathrm{O}\right]$ were used to prepare the nano $\mathrm{ZnO}$ powder. Metal nitrates and citric acid were dissolved in deionized water. Nitrate solutions were standardized through chemical analysis using ethylenediamine tetraacetic acid (EDTA) complexometric titration. Nitrate and citric acid solutions were mixed in 1:1 molar ratio of nitrates to citric acid. Then the solution was heated at $80^{\circ} \mathrm{C}$ to transform into gel. When ignited at any point of the gel, the dried gel burnt in a self-propagating combustion manner until all gels were completely burnt out to form a fluffy loose powder. The auto ignition of gel was carried out in BOROSIL glass beaker upon a hot plate. The autocatalytic nature of the combustion process has been studied by differential thermal analysis (DTA) and Thermogravimetry (TG) analysis using NETZSCH STA (Model No: 409C, UK) of the dried gels. Specific surface area of ash burnt $\mathrm{ZnO}$ powder was determined using Quantachrome Autosorb (Model No: Nova 1200 BET, USA). The as-burnt ash was calcined at $500^{\circ} \mathrm{C} / 2 \mathrm{~h}$ for better crystallization and homogeneous cation distribution in the spinal. As the auto-combustion rate is so rapid that the cations may not be well distributed in $\mathrm{ZnO}$ lattice of as-burnt ashes. Particle size and shape were analyzed from transmission electron microscopy (TEM) (Model No: CM 200, Phillips, Netherlands). For preparation of TEM sample, the powder was dispersed in isopropyl alcohol in a ultra sonication bath $(20 \mathrm{kHz}$, $500 \mathrm{~W}$ ) for half an hour. One drop of the well-dispersed sample solution was deposited on to a carbon coated copper grid (400 mesh). The dried grid was used for microscopy.

The resultant powder was mixed with various dopents with this typical recipe: $\mathrm{ZnO}-\mathrm{Bi}_{2} \mathrm{O}_{3}-\mathrm{Sb}_{2} \mathrm{O}_{3}-\mathrm{CoO}-\mathrm{MnO}_{2}-$ $\mathrm{Cr}_{2} \mathrm{O}_{3}-\mathrm{SiO}_{2}$ (96.5:0.5:1.0:0.5:0.5:0.5:0.5, in molar ratio). All additives were mixed in ball mill for 24h. The mixed powder was granulated using polyvinyl alcohol as a binder and was uniaxially pressed at a pressure of $214 \mathrm{MPa}$ to form pellet specimens. The specimens were sintered at $850^{\circ} \mathrm{C}$ to $1150^{\circ} \mathrm{C}$ in $100^{\circ} \mathrm{C}$ interval and held for $4 \mathrm{~h}$ respectively in air atmosphere. The bulk density and apparent porosity of sintered varistor was measured by Archimedes principle. The as-burnt ash and the sintered varistor were characterized with respect to phase identification, crystallite size and lattice parameter determination using X-ray diffraction (PW-1830, Philips, Netherlands) with $\mathrm{Cu}-\mathrm{K} \alpha$ radiation. The crystallite size was calculated from peak broadening using Scherrer formula. Microstructures details were analyzed by using Scanning Electron Microscope (SEM) (LEO 430i Stereoscan, UK) on the polished surface. The intercept length method was used to a mean grain size. Silver paste was printed on both sides of the sintered samples and then cured at $400^{\circ} \mathrm{C}$ in air for $30 \mathrm{~min}$ in preparation for the experiment to determine its electrical characterizations. Breakdown Voltage value was determined and non-linear co-efficient $\alpha$ was estimated by the following equation (Matsuoka, 1971).

$$
\alpha=1 / \log \left(\mathrm{V}_{1 \mathrm{~mA}} / \mathrm{V}_{0.1 \mathrm{~mA}}\right)
$$

Where, $\mathrm{V}_{1 \mathrm{~mA}} \& \mathrm{~V}_{0.1 \mathrm{~mA}}$ represent the voltage at $1 \& 0.1 \mathrm{~mA}$ respectively.

\section{Results and Discussion}

\subsection{Thermal Analysis}

The experimental observation reveled that the nitrate-citrate gels exhibited self-propagating combustion behavior. Figure 1 shows the DTA and TGA of the dried nitrate-citrate gel. There is one DTA endothermic peak at about $140^{\circ} \mathrm{C}$ and it may be due to the removal of residual water. This dehydration process is shown $4 \%$ weight losses in TG graph. The DTA exothermic peak at around $186^{\circ} \mathrm{C}$ may be caused by the autocatalytic anionic oxidation-reduction reaction of nitrates with citric acid, which initiates the formation of nano $\mathrm{ZnO}$ powder through the solid-state diffusion process (Gajbhiye et al., 1995). The nitrate-citrate combustion reaction is as follows:

$$
\mathrm{Zn}\left(\mathrm{NO}_{3}\right)_{2}+3 \mathrm{C}_{6} \mathrm{H}_{8} \mathrm{O}_{7}+2 \mathrm{O}_{2} \rightarrow \mathrm{ZnO}+\mathrm{N}_{2} \uparrow+6 \mathrm{CO}_{2} \uparrow+10 \mathrm{H}_{2} \mathrm{O}
$$

During combustion $\mathrm{CO}_{2}, \mathrm{~N}_{2}$ and $\mathrm{H}_{2} \mathrm{O}$ gasses are released. The thermo gravimetric analysis of the dried gels is exhibited a two-step weight loss. The weight loss at $50-140^{\circ} \mathrm{C}$ region corresponds to the dehydration of nitrate-citrate gel, while that at $186^{\circ} \mathrm{C}$ corresponds to the decomposition of nitrate-citrate dried gels as stated in the above reaction. The decomposition at $186^{\circ} \mathrm{C}$ is shown $17 \%$ weight losses in TG graph. This weight loss is attributed to the loss of residual nitrate and organic maters, not the actual nitrate and organic maters as stated in Equation 2. 


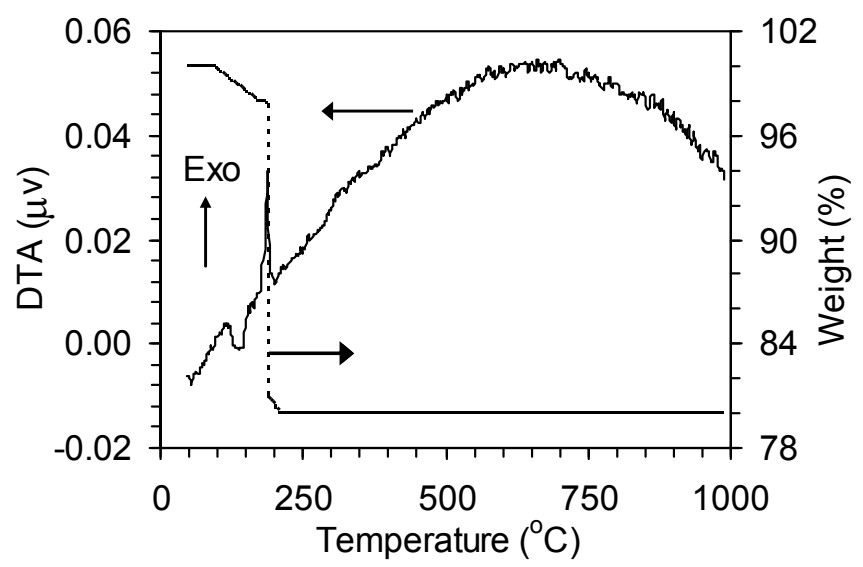

Figure 1. DTA/TG plots for the dry nitrate-citrate gel at $10^{\circ} \mathrm{C} / \mathrm{min}$ heating rate in air

\subsection{Phase and Structure Analysis}

The XRD analysis of $\mathrm{ZnO}$ synthesized by auto combustion method is shown in Figure 2. The as-burnt ash is characterized with respect to phase identification, crystallite size determination using X-ray diffraction with $\mathrm{Cu}-\mathrm{K} \alpha$ radiation. The crystallite size is calculated from peak broadening using Scherrer formula $\left(\mathrm{D}_{h k l}=0.9 \lambda\right.$ $\beta \operatorname{Cos} \theta$ ), where $D_{h k l}$ is the crystallite size perpendicular to $(h k l)$ plane, $\lambda$ is the wave length of $\mathrm{X}$-ray used, $\beta$ (rad) is the width of the diffraction peak and $\theta$ is the peak position. The full width at half maxima (FWHM) is used for $\beta$ and it is expressed as $\beta=\mathrm{B}-\mathrm{b}$, where $\mathrm{B}$ and $\mathrm{b}$ (instrumental broadening) are FWHM for sample and Si standard, respectively. Fully crystalline Si metal standard pellet, supplied with the Philips XRD system for calibration of the instrument, is used to measure the instrumental broadening (b) parameter.

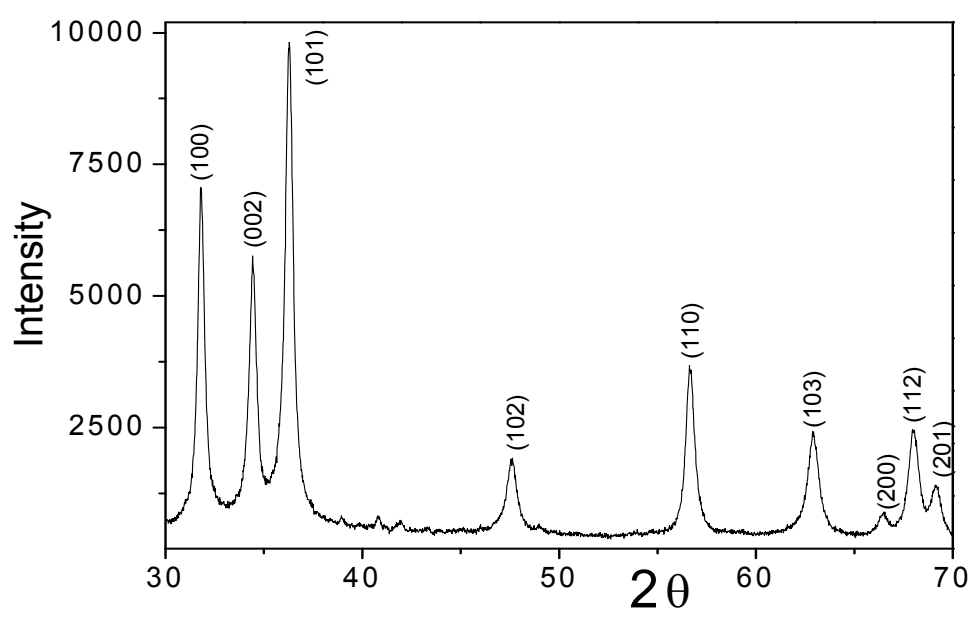

Figure 2. XRD patterns of as burnt $\mathrm{ZnO}$ Powder

The figure shows that the ZnO, similar to JCPDS card No. 36-1451, formed are in crystalline state. No second phase is detected by XRD. However, no metal $\mathrm{Zn}$ is discovered, which may be profited from the adequate and proper existence of $\mathrm{O}_{2}$ in the gas mixture. The crystallite size is calculated from peak broadening of (101) peak. The broad peaks in the XRD patterns indicate fine crystallite size of the $\mathrm{ZnO}$ particles. The crystallite size of as burnt ferrite powders is in the range $3-10 \mathrm{~nm}$. This observation reveals that the nanocrystalline $\mathrm{ZnO}$ powders can be synthesized directly by the auto-combustion of nitrate-citrate gels.

Surface area of as burnt $\mathrm{ZnO}$ powder is $40-45 \mathrm{~m}^{2} / \mathrm{gm}$. The TEM micrographs of the as-fabricated $\mathrm{ZnO}$ nanoparticles are given in Figure 3, showing almost homogeneous and uniform distribution of these particles in the powder samples. The particles consist of some regular and irregular polyhedrons with mean sizes of about $30-35 \mathrm{~nm}$. Shape of the particle is spherical and the average powder density is $3.01 \mathrm{gm} / \mathrm{cc}$. 


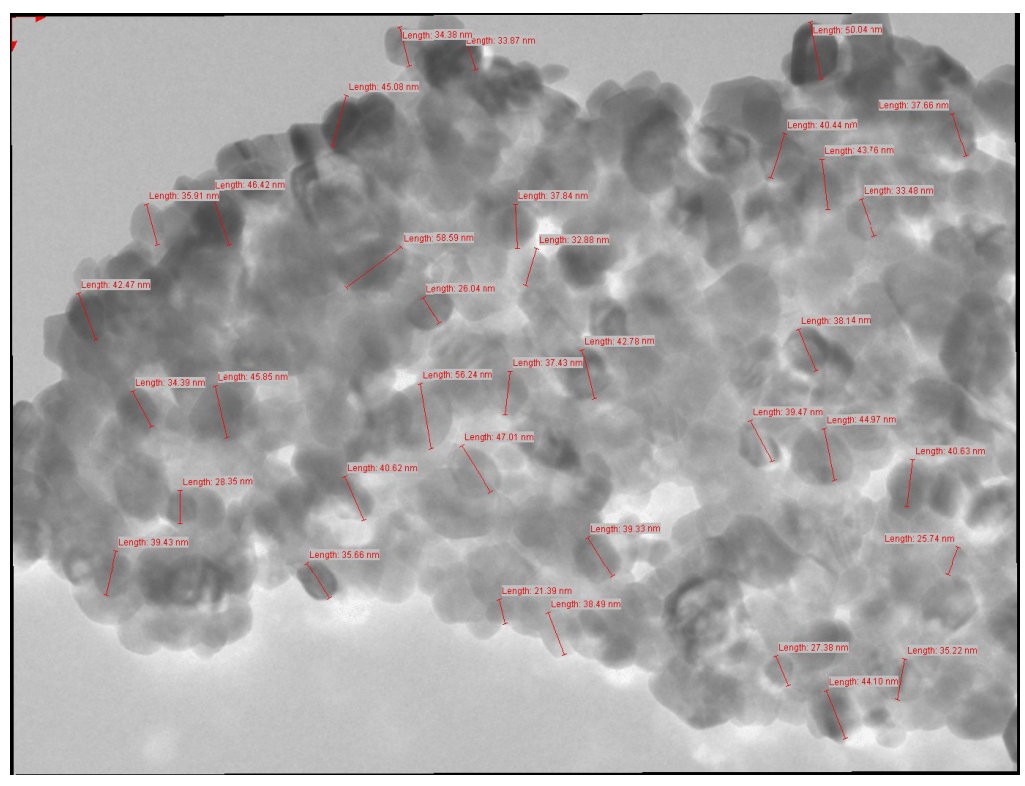

Figure 3. TEM patterns of as burnt $\mathrm{ZnO}$ Powder

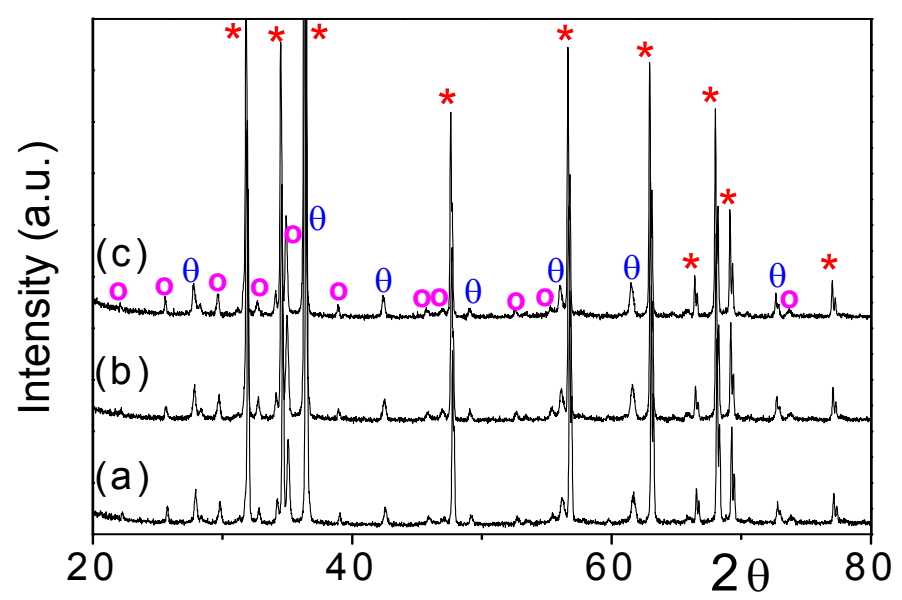

Figure 4. XRD patterns of the sintered $\mathrm{ZnO}$ Varistor with different sintering temperatures (a) $950^{\circ} \mathrm{C}$, (b) $1050^{\circ} \mathrm{C}$, (c) $1150^{\circ} \mathrm{C}\left(0-\right.$ Spinel Phase, $\boldsymbol{\theta}$ - Bi-rich Phase, ${ }^{*}$ - ZnO Phase)

The sintered $\mathrm{ZnO}$ varistors (Sintered at (a) $950^{\circ} \mathrm{C}$, (b) $1050^{\circ} \mathrm{C}$, (c) $1150^{\circ} \mathrm{C}$ ) are also characterized by $\mathrm{XRD}$, shown in Figure 4. As per expectation the crystiallity increases with successive heat treatment of the varistor. The figure shows that the broadening of diffraction peak decreases from 950 to $1150^{\circ} \mathrm{C}$ respectively. The crystallite size (Table 1) is also increased with sintering temperature. The crystallite sizes of sintered ferrites are in the range $80-145 \mathrm{~nm}$. This figure also shows the appearance of a variety of phases, including Bi-rich phase, Spinel phase and $\mathrm{ZnO}$ as mother phase. The intensity of Bi-rich phase and Spinel phase is increased with successive temperatures. 


\subsection{Densification \& Microstructure Study}

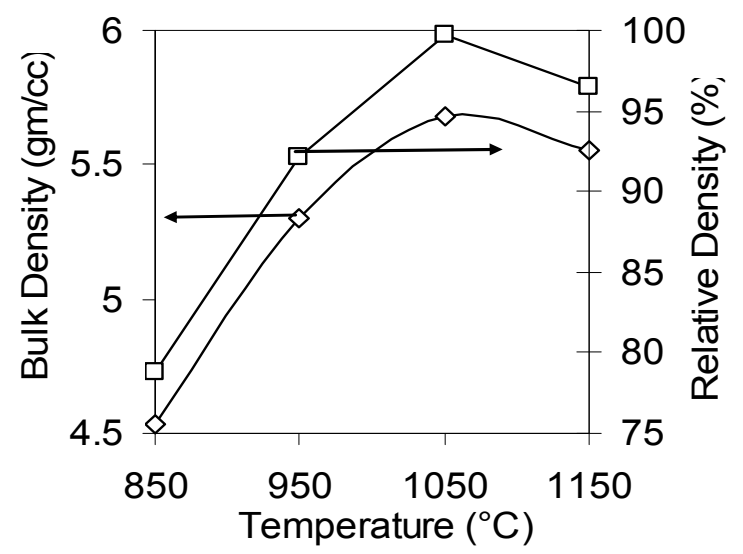

Figure 5. Variation of bulk density and relative density of $\mathrm{ZnO}$ Varistor at different sintering temperatures

Table 1. Apparent porosity, crystallite size and grain size of $\mathrm{ZnO}$ varistor samples at different sintering temperatures

\begin{tabular}{cccc}
\hline $\begin{array}{c}\text { Sintering Temperature } \\
\left({ }^{\circ} \mathrm{C}\right)\end{array}$ & Apparent Porosity & Crystallite Size $(\mathrm{nm})$ & $\begin{array}{c}\text { Grain Size } \\
(\mu \mathrm{m})\end{array}$ \\
\hline 850 & 24.61 & 80 & 2.27 \\
950 & 2.99 & 112 & 3.42 \\
1050 & 0.07 & 134 & 5.05 \\
1150 & 0.10 & 145 & 6.89 \\
\hline
\end{tabular}

Figure 5 shows the variation of bulk density and relative density at different sintering temperatures for the $\mathrm{ZnO}$ Varistor ceramic samples. As expected, bulk density increases and porosity (Table 1) decreases with temperature. The rate of increase in bulk density as well as the decrease in porosity up to $1050^{\circ} \mathrm{C}$ seems to be higher than at $1150^{\circ} \mathrm{C}$. The lower rate of densification at $1150^{\circ} \mathrm{C}$ may be due to the higher amount of $\mathrm{Zn}$-evaporation losses from the ceramics. In fact, this sample shows the presence of closed porosity in the range of $1-2 \%$. The pores are entrapped within the grains due to the higher rate of grain growth (Table 1) at that temperature. It is difficult to remove porosity completely due to increased $\mathrm{Zn}$-evaporation loss at higher temperature.

Figure 6 shows the SEM microstructure of $\mathrm{ZnO}$ Varistor ceramics at different sintering temperatures. The ceramics usually consist of $\mathrm{ZnO}, \mathrm{Zn}_{7} \mathrm{Sb}_{2} \mathrm{O}_{12}$ spinel and $\mathrm{Bi}_{2} \mathrm{O}_{3}$-rich phases, which suggests that the microstructure development is mostly governed by the phase equilibria in the ternary system $\mathrm{ZnO}-\mathrm{Bi}_{2} \mathrm{O}_{3}-\mathrm{Sb}_{2} \mathrm{O}_{3}$ (Olsson et al. 1993; Melo et al. 1990; Inada, 1980). Part of the grain growth inhibition is due to the formation of the spinel phase whose particles pin down the grain boundaries. If the grain boundaries pinning spinel particles are formed early during the sintering process, when the $\mathrm{ZnO}$ particles are very small and similar in size, the particle drag mechanism, which reduces the grain growth rate, also prevents the occurrences of discontinuous or abnormal grain growth. Thus, it is very important that the element distribution in the microstructure in highly homogenous, which must be achieved prior to sintering, during the powder preparation process. The average grain size is 5-7 $\mu \mathrm{m}$. Figure 6 (c) shows uniform distribution of 3 different phases. Below $1050^{\circ} \mathrm{C}$ the secondary phases are not formed properly. Elementary composition analysis by EDS confirms that the Bi content is higher near the grain boundary than on the matrix, indicating the formation of a Bi-rich phase along with $\mathrm{ZnO}$ grain boundaries. 

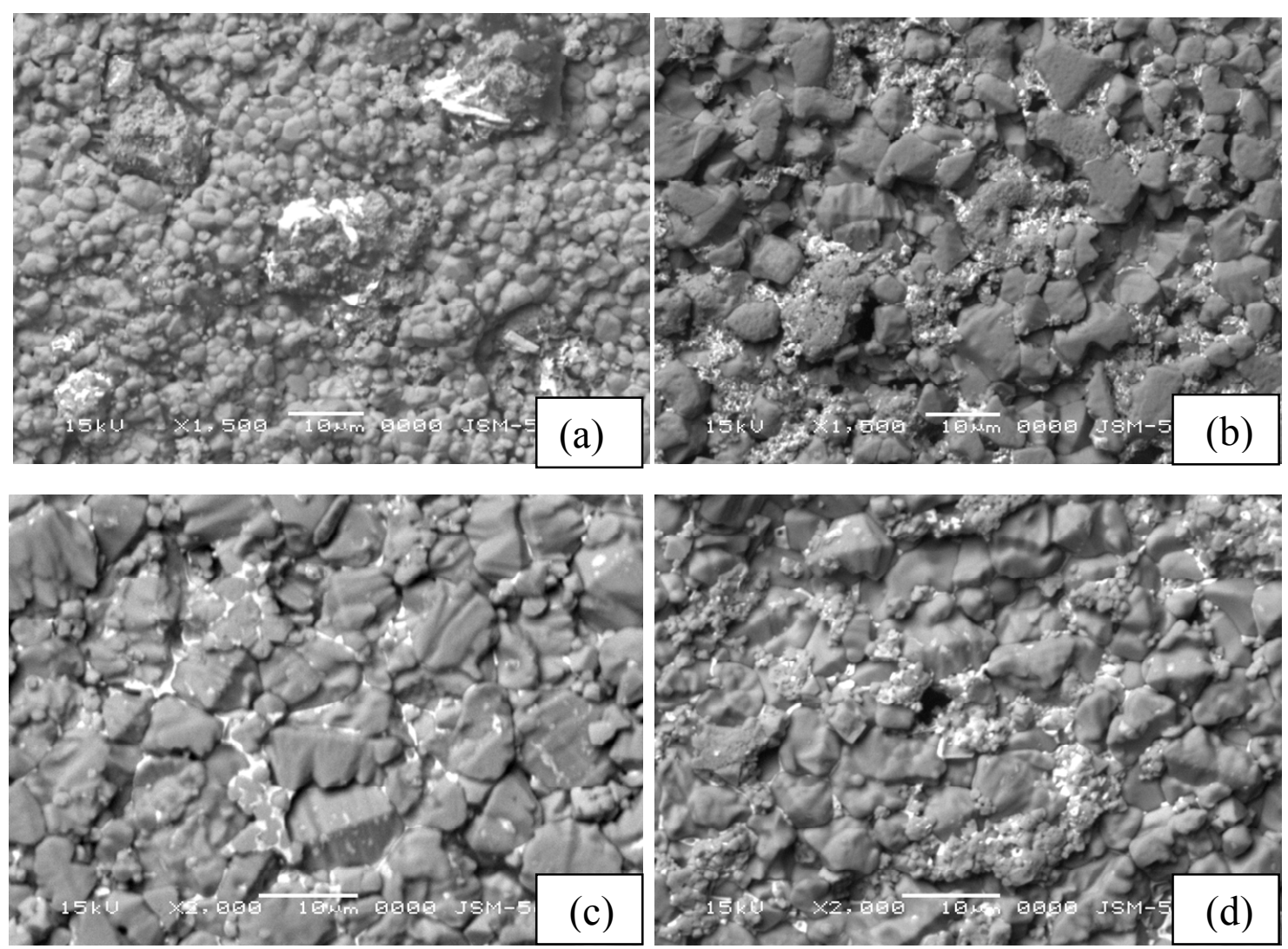

Figure 6. SEM photographs of sintered $\mathrm{ZnO}$ Varistor with different sintering temperatures (a) $850^{\circ} \mathrm{C}$, (b) $950^{\circ} \mathrm{C}$, (c) $1050^{\circ} \mathrm{C}$, and (d) $1150^{\circ} \mathrm{C}$

\subsection{Electrical Property Study}

Table 2. Breakdown field at $1 \mathrm{~mA} \& 0.1 \mathrm{~mA}$ along with breakdown voltage and non-linear co-efficient of nano based varistor at different temperatures

\begin{tabular}{ccccc}
\hline Sintering Temperature $\left({ }^{\circ} \mathrm{C}\right)$ & $\mathrm{V}_{\text {lmA }}(\mathrm{kV})$ & $\begin{array}{c}\mathrm{V}_{0.1 \mathrm{~mA}} \\
(\mathrm{kV})\end{array}$ & $\begin{array}{c}\text { Breakdown Voltage } \\
(\mathrm{V} / \mathrm{mm})\end{array}$ & $\alpha$ \\
\hline 850 & 2.32 & 2.04 & 233.26 & 18 \\
950 & 2.36 & 2.10 & 237.35 & 20 \\
1050 & 2.81 & 2.66 & 292.58 & 42 \\
1150 & 2.61 & 2.46 & 264.86 & 38 \\
\hline
\end{tabular}

The as prepared sample possesses good electrical characterization of varistors, with high non-linear coefficient and high breakdown voltage. Table 2 shows the variation of non linear co-efficient, breakdown voltage and breakdown field as a function of temperature. It shows that the breakdown voltage changes with temperatures. Initially it increases than decreases at higher temperature. This may be due to for higher grain size (Table 1), as we know breakdown voltage inversely proportion to grain size (Levinson, 1988). The addition of dopents to a nano based varistor decreases the grain size of $\mathrm{ZnO}$ ceramic. The diffusion of excess oxygen ions into the $\mathrm{ZnO}$ grain boundaries has been noted as the important acceptor like defects that account for the double Schottky barrier of $\mathrm{ZnO}$ varistor. The amount of oxygen adsorbed per unit volume of $\mathrm{ZnO}$ increases as the grain size decreases, which leads to a higher breakdown voltage. The breakdown voltage is lower at lower temperature $\left(850^{\circ} \mathrm{C}, \& 950^{\circ} \mathrm{C}\right)$ may be due to absence of sufficient secondary phases into the matrix. The smaller value of $\alpha$ at lower temperature resulted from a lower barrier height because of the increase in electron concentration in the $\mathrm{ZnO}$ grains. 


\section{Conclusion}

Ultra fine Zinc Oxide powders with nano crystallites size have been prepared by sol-gel auto combustion method. The combustion synthesis route enables synthesis at low temperature and the products obtained were in a finely divided state with large surface areas. The additives were found to be already playing their expected roles like sintering aids, grain growth inhibitors, etc. All the microstructures consisted of $\mathrm{ZnO}$ grains along with Spinel and Bi-rich phases as secondary phases. The varistor can be produced having a sintered density $\sim 99 \%$ of its theoretical density with grain size $\sim 5-7 \mu \mathrm{m}$ and a maximum breakdown voltage $292 \mathrm{~V} / \mathrm{mm}$ at $1050^{\circ} \mathrm{C}$. The nonlinear coefficient reaches up to 42 . Moreover, using this nano $\mathrm{ZnO}$ powder lower the sintering temperature $\left(1050^{\circ} \mathrm{C}\right)$ compare to conventional process $\left(1200^{\circ} \mathrm{C}\right)$. These elements are applicable to high voltage arrestors for power systems.

\section{Acknowledgement}

P. K. Roy wishes to thank the Crompton Greaves Ltd, Mumbai, for providing financial support through project grant.

\section{References}

Asokan, T., Iyengar, G. H. K., \& Nagabhushana, G. R. (1987). Studies on microstructure and density of sintered ZnO-based non-linear resistors. J. Mater. Sci., 22(6), 2229-2236. http://dx.doi.org/10.1007/BF01132965

Boutonet, M., Kizling, M., Stenius, P., \& Maire, G. (1982). The preparation of monodisperse colloidal metal particles from microemulsions. Colloids Surf., 5, 209-225. http://dx.doi.org/10.1016/0166-6622(82)80079-6

Gajbhiye, N. S., Bhattacharya, U., \& Darshane, V. S. (1995). Thermal decomposition of zinc-iron citrate precursor. Thermochimica Acta, 264, 219-230. http://dx.doi.org/10.1016/0040-6031(95)02331-U

Gupta, T. K. (1990). Application of zinc oxide varistor. J. Am. Ceram. Soc., 73, 1817-1840. http://dx.doi.org/10.1111/j.1151-2916.1990.tb05232.x

Hennings, D. F. K., Hartung, R., \& Reijnen, P. J. L. (1990). Grain size control in low-voltage varistors. J. Am. Ceram. Soc., 73, 645-648. http://dx.doi.org/10.1111/j.1151-2916.1990.tb06566.x

Inada, M. (1980). Formation mechanism of nonohmic zinc oxide ceramics. Jpn. J. Appl. Phys., 19, 409-419. http://dx.doi.org/10.1143/JJAP.19.409

Konno, K., Koide, M., \& Kitahara, A. (1984). Preparation of barium carbonate particles using a W/O microemulsion. J. Chem. Soc. Jpn., 6, 815-822. http://dx.doi.org/10.5923/j.materials.20120201.02

Levinson, L. M. (1988). Electronic ceramics: properties, devices and applications. Marcel Dekker.

Matsuoka, M. (1971). Nonohmic Properties of Zinc Oxide Ceramics. Jpn. J. Appl. Phys., 10, 736-46. http://dx.doi.org/10.1143/JJAP.10.736

Melo, T. J. A., Costa, G., Bressiani, A. H. A., \& Kiminami, R. H. G. (1990). Proceedings of the 34th Brazilian congress on ceramics, 1, 107-114.

Olsson, E., Dunlop, G., \& Osterlund, R. (1993). Development of functional microstructure during sintering of a $\mathrm{ZnO}$ varistor material. J. Am. Ceram. Soc., 76(1), 65-71. http://dx.doi.org/10.1111/j.1151-2916.1993.tb03690.x

Rahaman, M. N., DeJonghe, L. C., Voight, J. A., \& Tuttle, B. A. (1990). Low temperature sintering of zinc oxide varistors. J. Mater. Sci., 25, 737-42. http://dx.doi.org/10.1007/ BF00714102

Siegel, R. W. (1990). Mater. Res. Bull., 15(10), 60.

Snow, G. S., White, S. S., Cooper, R. A., \& Armijo, J. R. (1980). Characterization of high field varistors in the system $\mathrm{ZnO}-\mathrm{CoO}-\mathrm{PbO}-\mathrm{Bi}_{2} \mathrm{O}_{3}$. Am. Ceram. Soc. Bull., 59(6), 617-622. 